\title{
Crop Situation in India, Before, During and After COVID-19 Lockdown, as Seen from the Satellite Data of Resourcesat-2 AWiFS
}

\author{
Shalini Saxena ${ }^{1} \cdot$ Amit Rabha $^{1} \cdot$ Preeti Tahlani $^{1} \cdot$ Shibendu S. Ray $^{1}$ (D)
}

Received: 7 September 2020 / Accepted: 12 October 2020/Published online: 27 October 2020

(C) Indian Society of Remote Sensing 2020

\begin{abstract}
In this study, an attempt has been made to assess the crop situation in India, before the COVID-19 pandemic lockdown, during the lockdown and after the lockdown. In India, the lockdown was imposed from 24 March to 31 May 2020. That was the period of harvesting of Rabi (winter) season crop and sowing of Zaid (summer) season crop. However, the government announced a large number of measures to provide relaxation to agricultural activities during the lockdown. A satellite remote sensing-based assessment was carried out to see the impact of the lockdown and government measures. Normalized Difference Vegetation Index (NDVI) time composite all-India product derived from Resourcesat-2/2A Advanced Wide Field Sensor for February, May, and July 2020 was used to assess the crop situation, representing three crop seasons, i.e. Rabi, Zaid and Kharif (rainy). NDVI images of 2020 were compared with corresponding images of 2019. Change images were generated, and state-level NDVI values were computed. The state-level cropped area proportion was also mapped using the NDVI thresholding approach. The crop sown area statistics, crop cutting experiment (CCE) numbers and rainfall data were also compared for both the years. It was observed that the differences were very low between the NDVI of 2019 and 2020 in February month. However, the differences were high in many states during May and in most of the states during July. A statistical test of significance (paired $t$ test) was carried out for state-level NDVI and crop area values, which validated this result. This NDVI change was mostly due to increased crop area during Zaid and Kharif (rainy) seasons and higher rainfall from May to July. The satellite and other data (crop area and CCE numbers) analysis also showed the sowing and harvesting operations in major parts of the country went on smoothly, during the lockdown period.
\end{abstract}

Keywords Remote sensing · Normalized Difference Vegetation Index (NDVI) · COVID-19 · Lockdown ·

Agriculture · India

\section{Introduction}

The COVID-19 pandemic caused a large-scale global impact this year (Elavarasan and Pugazhendhi 2020), with more than 34.8 million cases and more than 1.0 million deaths, as on 4 October 2020 (WHO 2020). This forced various national governments to impose strict lockdown conditions to control the spread of the disease. In India, the lockdown was imposed for a long period of more than 2 months, i.e. from 25 March to 31 May (Patel et al. 2020).

Shibendu S. Ray

shibendu.ray@gmail.com; shibendu.ncfc@nic.in

1 Mahalanobis National Crop Forecast Centre, DAC\&FW, New Delhi 110 012, India
All socio-economic activities were suspended during the lockdown period, except for the essential activities. Considering agriculture as an essential and time-bound activity affecting a large fraction of the population, the government made agricultural activities, including farming operations by farmers and farmworkers in the field, fully functional from 20 April. This helped in the smooth functioning of Rabi (winter) crop harvest and Zaid (summer) crop sowing activities. India also declared a host of welfare measures to protect vulnerable people, including smallholder farmers, agricultural labourers, and migrant workers (Padhee and Pingali 2020).

India has three major cropping seasons called Kharif/ Rainy (June to October), Rabi/Winter (November to April), and Zaid/Summer (April to June/July). Thus, before 
lockdown Rabi season was going on and crop harvesting was scheduled during the lockdown period. The Zaid season sowing was to take place during the lockdown. By the time Kharif sowing started, the lockdown was over. The major crops during the Kharif season are rice, cotton, sugarcane, groundnut, soybean, pigeon pea and coarse cereals. During Rabi season, the important crops are wheat, rapeseed \& mustard, gram, sorghum and rice. Crops such as rice, pulses and coarse cereals are mostly grown in the Zaid season. The cropping pattern of a region depends on its soil, water availability, climatic factors (Singh et al. 2011), socio-economic, political, and historical factors (Wardlow and Egbert 2002). Though crop production is mostly sensitive to rainfall, the economic variables and the government policies, which can modulate subsidies and support prices, also have control over food production (Ghosh et al. 2019). Hence, to understand the crop situation, there is a need to analyse the weather data and the government policies.

Satellite remote sensing is one of the most effective tools that can provide precise and up-to-date information on the crop situation. The main advantage of remote sensing from satellites is the synoptic and repeated collection of data, which allows retrieval of time-series and reliable information on the temporal and spatial pattern of crop area and crop condition over large areas (Bastiaanssen et al. 2000; Dadhwal et al. 2002; Panigrahy and Ray 2006). While high-resolution sensors provide detailed information about small areas, the sensors with moderate spatial resolution and high temporal revisits allow monitoring of crop situations in a large area. The Indian satellite Resourcesat2/2A borne Advanced Wide Field Sensor (AWiFS) data having a spatial resolution of $56 \mathrm{~m}$ at nadir and a swath of $740 \mathrm{~km}$ with 5-day revisit time have been utilized for various resource monitoring activities (Ray and Neetu 2017). The all-India Normalized Difference Vegetation Index (NDVI) product derived using the algorithm developed by Misra et al. (2012) is highly suitable for vegetation studies on a national scale. NDVI image is often useful because of its high correlation with crop biomass, vigour and canopy cover (Son et al. 2012; Zhang et al. 2011). The AWiFS NDVI product, which is available with 10- or 15-day composites, has been operationally used for many agricultural applications, such as crop estimation (Ray and Neetu 2017), drought assessment (Saxena et al. 2019) and extreme weather impact assessment (Ray et al. 2016).

There have been many satellite-based studies for studying the impact of lockdown in India, especially on environmental implications like air quality (Singh and Chauhan 2020) and water quality (Garg et al. 2020). Additionally, there have been a few publications on possible impacts COVID-19 on Indian agriculture (Dev 2020; Kumar et al. 2020; Padhee and Pingali 2020). However, there was no study to show the impact of lockdown on the cropping pattern, especially using satellite remote sensing data.

In India and many other countries, crop cutting experiments (CCEs) are carried out to measure crop yields, for production estimation and crop insurance (NSSO 2007; Ray and Dubey 2018). In a CCE, the crop is cut from a randomly selected plot (generally $5 \times 5 \mathrm{~m}^{2}$ ), and grains are harvested, threshed, dried and weighed. A multiplication factor is used to convert the weight of the grains to per hectare yield. Under the Government of India's flagship crop insurance programme PMFBY, a large number of CCEs are conducted in the country to estimate yield at the Insurance Unit level for insurance claim computation (DAC\&FW 2016). The number of CCEs conducted gives an indication about the harvesting operations.

In this context, this current study was carried out to assess the crop situation before (Rabi season), during (Zaid season) and after (Kharif season) the COVID-19 lockdown using Resourcesat 2 AWiFS all-India NDVI products and crop (crop area statistics and number of CCEs) and weather (rainfall) data. The current year's situation was compared with the previous year (2019).

\section{Materials and Methods}

All-India Resourcesat 2/2A NDVI products for February, May, and July, representing Rabi, Zaid, and Kharif seasons, respectively, were procured from National Remote Sensing Centre (NRSC), ISRO with a temporal frequency of 15 days ( 2 products in a month) for the years 2019 and 2020. The year 2019 was selected for comparison purposes as it was not only the previous year, it was also agriculturally a normal year. The NDVI products are of 56-m spatial resolution. In total, there were 12 NDVI products (2 years, 3 months in each year, and 2 fortnights in each month). The two fortnightly products of each month were combined to generate monthly products, using the maximum value compositing (MVC) method (Holben 1986). The agriculture area mask derived from NRSC's land-use land-cover (LULC) map of a 1:250,000 scale (NRSA 2007) was overlaid on the AWiFS NDVI products to extract NDVI maps for the agricultural area only. NDVI images were used for visualization of green vegetation during February, March, and July 2019 and 2020. To assess the change in NDVI, between respective months of 2020 and 2019, NDVI deviation percentage maps were generated, as given below.

$\mathrm{NDVI}_{\text {Dev }}(\%)=\frac{\mathrm{NDVI}_{2020}-\mathrm{NDVI}_{2019}}{\mathrm{NDVI}_{2019}} \times 100$ 
The deviation per cent was divided into three classes (increase, no change, and decrease), as given in Table 1.

The average NDVI value for each major agricultural state was computed for different months of 2019 and 2020 and compared graphically.

To find the cropped area in different NDVI images, a thresholding approach was used. Various authors have used the NDVI thresholding approach for crop area assessments (Basnyat et al. 2004; Xiao et al. 2006). Mondal et al. (2014), using Resourcesat 2 LISS III data, found that the NDVI threshold value for vegetative pixels was $>0.39$ in Kharif, $>0.23$ in Rabi and $>0.25$ in Zaid seasons. Patel and Oza (2014) analysed multi-temporal MODIS data and found that if it was a cropped area, then NDVI should be greater than 0.3. Accordingly, the NDVI threshold value of 0.3 was used to extract the crop area in each season for 2019 and 2020. However, as this value was derived from the literature survey and not based on ground truth, instead of crop area, crop area proportions, i.e. crop area divided by the total agricultural area (taken from NRSC LULC map), were estimated and compared. Figure 1 provides the flow diagram of the steps followed in the satellite data analysis. Satellite image analysis was carried out using ERDAS Imagine image processing software.

A paired $t$ test was carried out to assess the statistical significance of the differences in state-level NDVI values and crop area proportions between 2019 and 2020.

In addition to satellite data, crop-wise state-level area statistics were also collected from the Crops Division of Department of Agriculture, Cooperation \& Farmers Welfare (DAC\&FW), Ministry of Agriculture \& FW, for the Kharif and Zaid seasons. Crop production statistics were also collected from the Directorate of Economics \& Statistics (DES) for the Rabi season. The crop statistics of 2019 and 2020 were compared to validate the remote sensing-based interpretations.

A large number of crop cutting experiments are carried out in the country for yield estimation under the government's flagship crop insurance programme, Pradhan Mantri Fasal Bima Yojana, PMFBY (Prime Minister's Crop Insurance Plan). The number of CCEs conducted during Rabi seasons of 2020 and 2019 was collected from the

Table 1 NDVI deviation categories of 2020 data with respect to 2019 data

\begin{tabular}{ll}
\hline Deviation & Category \\
\hline$\leq-5 \%$ & Decrease in NDVI \\
$-5 \%$ to $+5 \%$ & No change in NDVI \\
$>+5 \%$ & Increase in NDVI \\
\hline
\end{tabular}

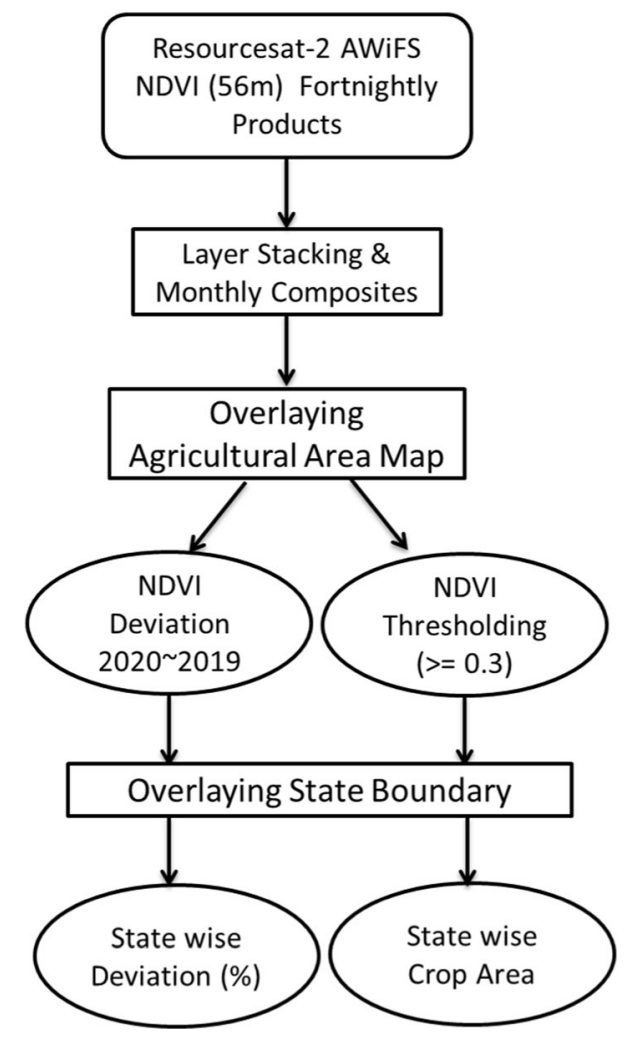

Fig. 1 Flow diagram of steps used for satellite data analysis

PMFBY cell to assess the impact of lockdown on harvesting operations.

National- and state-level rainfall data obtained from the India Meteorological Department (IMD), Crop Weather Watch Group of DAC\&FW (CWWG 2020), and MNCFC's drought project (Saxena et al. 2019) were also used for a year-to-year comparison. District-level rainfall deviation data were collected from IMD, and maps were generated in GIS.

\section{Results}

\section{Rainfall Situation}

The cumulative rainfall remained above normal (long-period average) throughout the period from 1 March to 30 May 2020. Central India received 104\% higher rainfall than the average, the north-west region received $31 \%$ higher, eastern and north-eastern India got 6\% higher, while the Southern peninsula received $4 \%$ lower rainfall. The district-level rainfall deviation map showed that for most of the districts of the country, except parts of Andhra Pradesh, Telangana, Gujarat and the north-east, the rainfall was normal ( -19 to $+19 \%$ deviation) or excess $(\geq+20 \%$ deviation) (Fig. 2). 


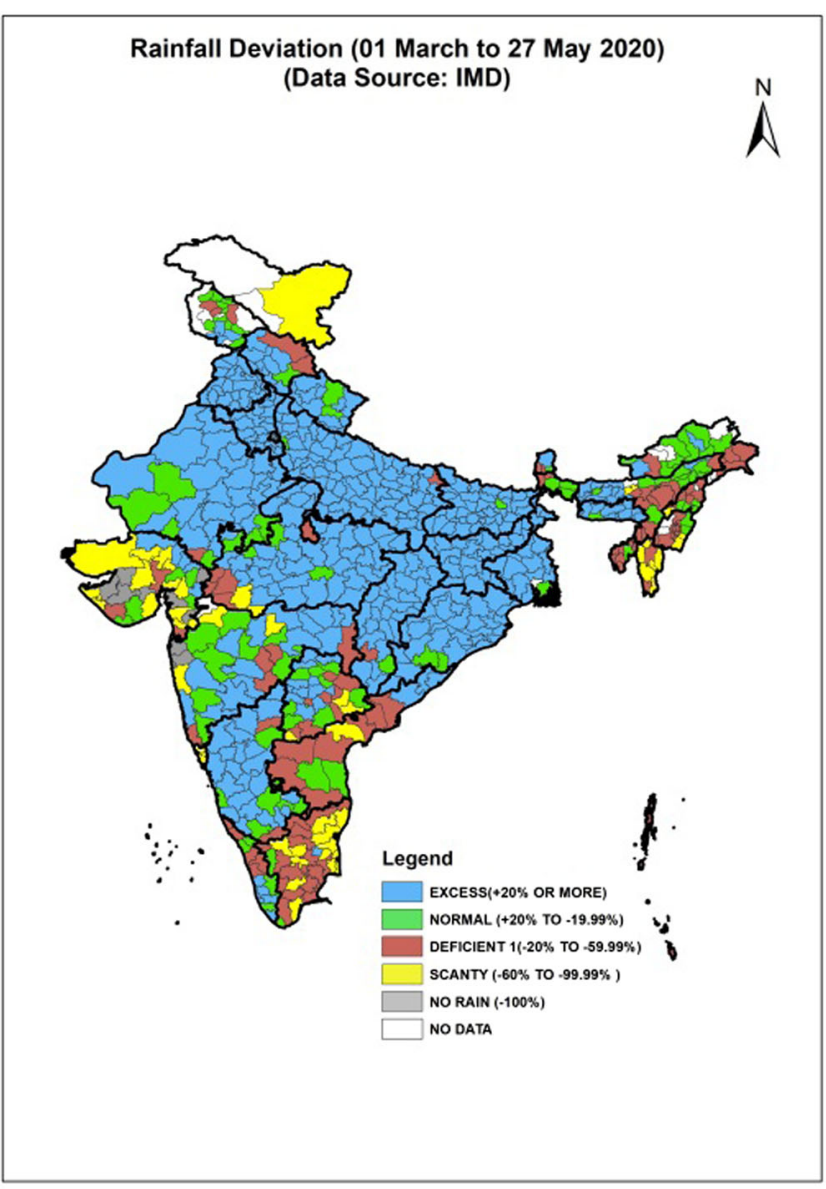

(a)

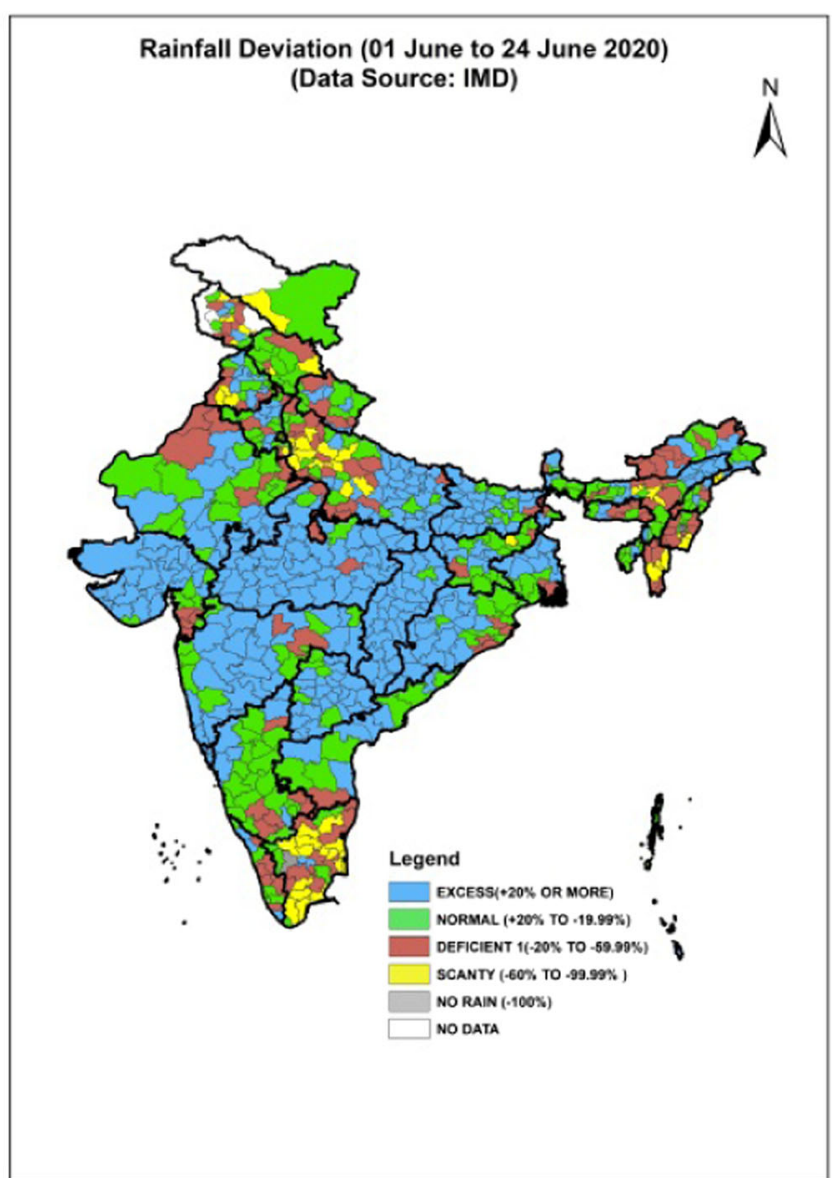

(b)

Fig. 2 District-wise rainfall deviation (\%) (maps for the periods a 1 March to 31 May 2020) and b 1 to 30 June 2020. Source: India Meteorological Department

Similarly, from 1 June to 29 July, the cumulative rainfall was $1 \%$ higher than the long-period average. However, from 1 June to 1 July, when the sowing for Kharif season starts, the rainfall at all-India level was $15 \%$ higher than the average. The district-level deviation maps show that, except for some parts of Uttar Pradesh, Tamil Nadu, Rajasthan and north-eastern states, most of the districts had normal or excess rainfall.

A comparison of 2 years' rainfall situation showed that there were a larger number of meteorological subdivisions with excess/large excess or normal rainfall in 2020 compared to 2019. Out of 36 meteorological subdivisions in the country, 29 subdivisions had normal or excess/large excess rainfall from 1 March to 31 May and from 1 June to 31 July, while in 2019 the numbers were 13 and 22, respectively (Table 2). This showed a much better rainfall situation in 2020 during the whole Zaid season and the sowing period of Kharif season, compared to 2019.

Since only $47.2 \%$ of the net sown area of the country is irrigated, the crops grown in Zaid and Kharif season are highly dependent upon rainfall. Hence, this high rainfall during March to May and June-July has resulted not only in an increase in crop area but may also result in an increase in crop vigour and production in both Zaid and Kharif seasons.

\section{Crop Area}

The season-wise comparison of the area of crops/crop groups between 2020 and 2019 is presented in Fig. 3. Though during the Rabi season, i.e. before lockdown, there has been an increase in area, the increase was between 0 and $17 \%$ for different crops with an overall increase of $9.5 \%$. In fact, for oilseeds, the area showed a decrease though it was very low $(0.09 \%)$. However, during the Zaid season, i.e. during the lockdown period, most of the crop/ crop groups showed an increase in the area of more than $25 \%$ compared to 2019 . The overall increase of area for all the crops during the Zaid season was $35 \%$, compared to 2019. The major increase in the Rice area was found in 
Table 2 Number of meteorological subdivisions (total 36) under different categories of rainfall situations. Source: India Meteorological Department

\begin{tabular}{|c|c|c|c|c|c|c|}
\hline \multirow[t]{2}{*}{ Rainfall category* } & \multicolumn{2}{|c|}{1 March-31 May } & \multicolumn{2}{|c|}{1 June-30 June } & \multicolumn{2}{|c|}{1 June-31 July } \\
\hline & 2019 & 2020 & 2019 & 2020 & 2019 & 2020 \\
\hline Excess/large excess & 04 & 14 & 03 & 14 & 03 & 11 \\
\hline Normal & 09 & 15 & 02 & 15 & 19 & 18 \\
\hline Deficient/large deficient & 23 & 7 & 31 & 7 & 14 & 7 \\
\hline
\end{tabular}

*These categories have been defined by India Meteorological Department, based on the deviations with respect to long-period average

Large excess: $60 \%$ or more, excess: $20-59 \%$, normal: $-19-19 \%$, deficient: $-20 \%$ to $-59 \%$, large deficient: $-60 \%$ to $-99 \%$

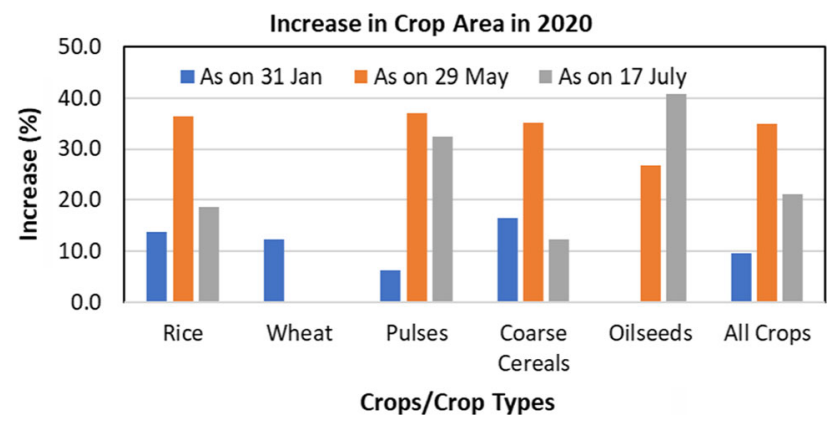

Fig. 3 All-India crop area increase (\%) in 2020, compared to 2019, in three different cropping seasons, i.e. Rabi (Jan data), Zaid (May data) and Kharif (July data). Source: Crops Division, Department of Agriculture, Cooperation \& Farmers' Welfare

Karnataka and Telangana states, while the pulses area increased mostly in Madhya Pradesh, Bihar and the Tamil Nadu states. The oilseeds area increase was mostly found in Gujarat and Maharashtra, while the coarse cereals area increased mostly in West Bengal, Uttar Pradesh and Maharashtra.

Similarly, during the Kharif season (i.e. post-lockdown period), as per the sowing progression data of 17 July 2020 , there was an increase in overall crop sowing of $21.2 \%$, compared to the same period in 2019. All crops/crop groups together showed an increase of more than $12 \%$, while Kharif pulses and oilseeds showed an increase of more than $30 \%$. As per government statistics, 4.8 million ha higher Kharif area coverage was reported in 2020 (as on 1 October), i.e. 112.2 million ha as compared to 107.3 million ha of the previous year. More area coverage was reported for rice, pigeon pea, mung bean, groundnut, soybean and cotton.

\section{Crop Cutting Experiments (CCEs)}

Under PMFBY, the CCE data are collected using an Android App (CCE-Agri) and are uploaded to a central server in real time. These PMFBY CCE data are used for crop insurance purpose. The number of CCEs conducted also indicates the success of the harvesting operations. A comparison of the number of CCEs conducted, under PMFBY, showed that during the Rabi season of 2019-2020 the number of CCEs was 274,769, while in 2018-2019 it was 276,261 . The Rabi season CCEs are generally conducted from March to May. Thus, from March to May of 2020, most of which was a lockdown period, there was no significant reduction (only 0.5\%) in the number CCEs conducted compared to the similar period in 2019. It indirectly showed that the government policy of relaxation for agricultural activities has helped to smoothen the harvesting operations, and therefore, there was no reduction in CCE numbers.

\section{Satellite Image Interpretation}

The Normalized Deviation Vegetation Index (NDVI) images derived from Resourcesat 2 AWiFS data for February, May and July representing pre-lockdown (Rabi season), lockdown (Zaid season) and post-lockdown (Kharif season) periods for the year 2020 are presented in Fig. 4, along with the images of the similar period of 2019. These NDVI values are only for the agricultural area, as agriculture mask has been used.

NDVI is a proven indicator of vegetation condition or crop health (Rouse et al. 1974). The higher green and blue regions in May and July indicate higher crop areas and better crop conditions during this period. Even in February, i.e. before lockdown, the crop condition was better in the central and southern states because of good post-monsoon rainfall in 2019, which resulted in good soil moisture, helping the growth of rainfed Rabi season crops.

The NDVI difference image of 2020 vis-à-vis 2019 shows that most of the area during May and July have more than 5\% positive NDVI deviation compared to the previous year. During May, most of the eastern and southern states had higher NDVI in 2020 as compared to 2019. In July, in the NDVI change image, most of the states have a bluish tinge, showing an increase in NDVI compared to 2019.

The state-wise NDVI comparisons, between 2019 and 2020, for February, May and July, are presented in Fig. 5. The comparison of NDVI values of 17 States shows that 


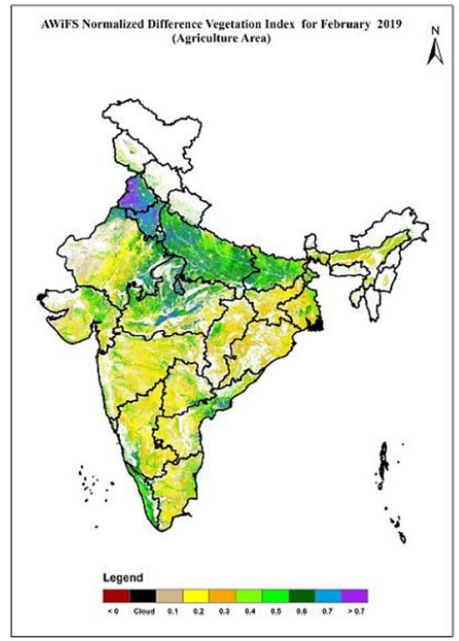

February 2019
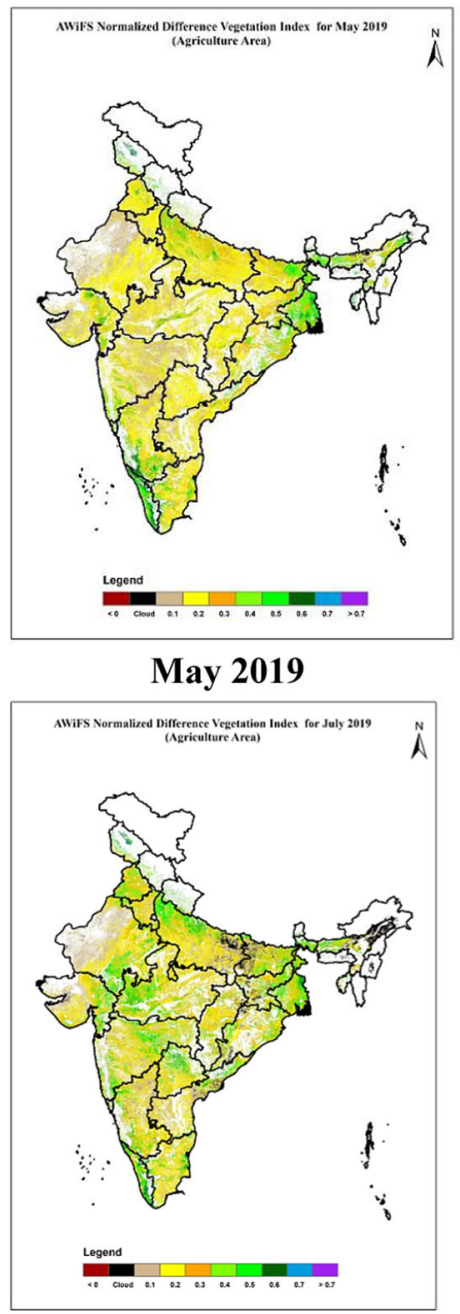

July 2019

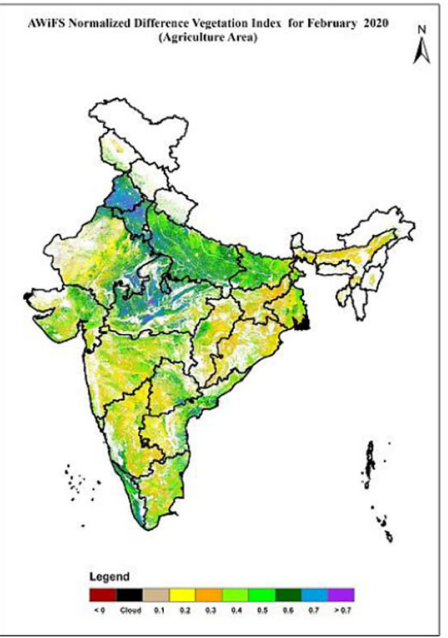

February 2020

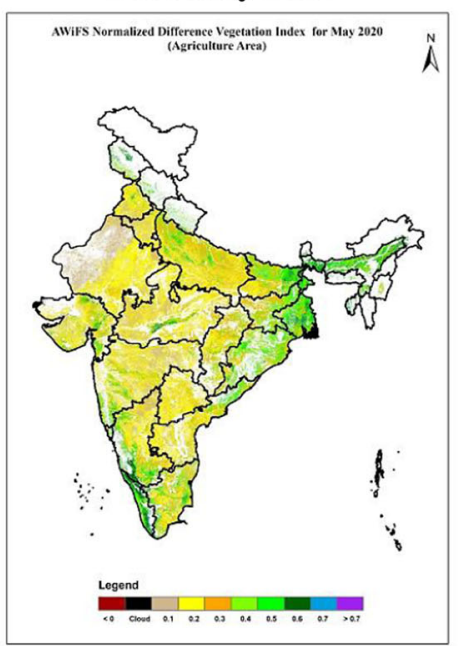

May 2020

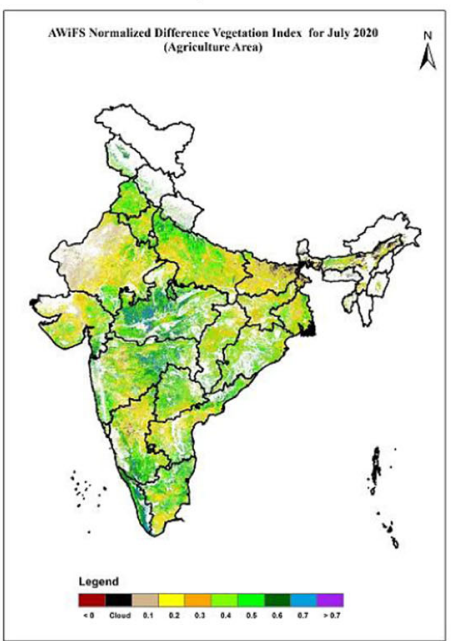

July 2020

Legend

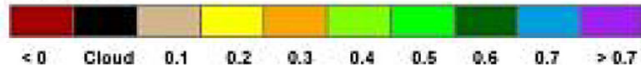

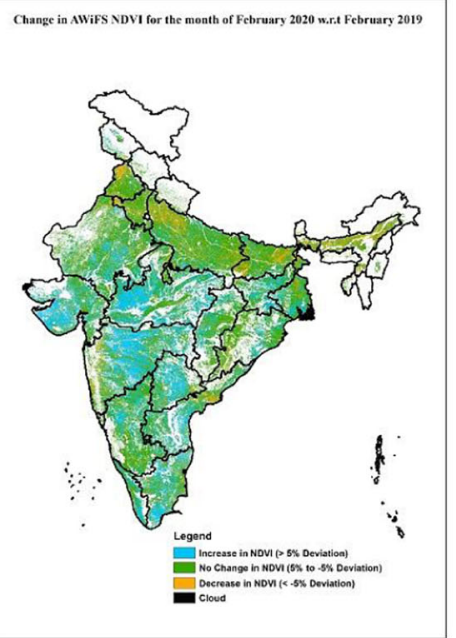

Change in NDVI

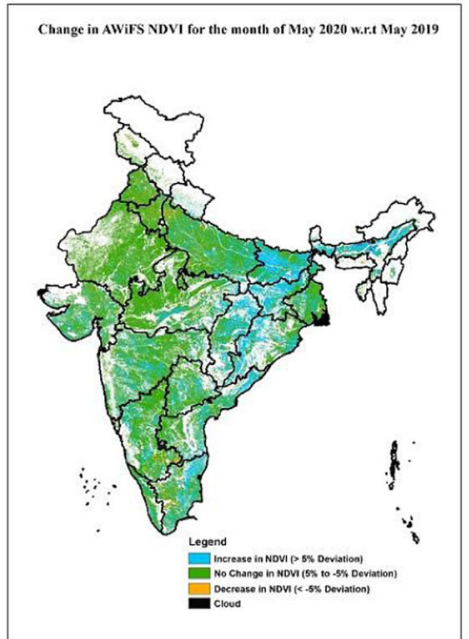

Change in NDVI

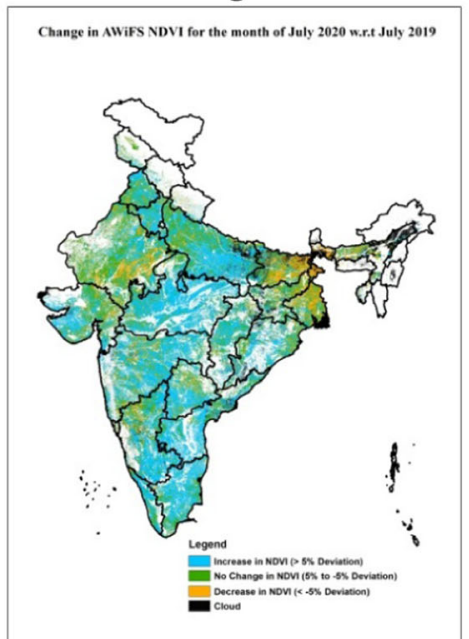

\section{Change in NDVI}

Increase in NDVI (> 5\% Deviation) No Change in NDVI ( $5 \%$ to $-5 \%$ Deviation) Decrease in NDVI (< -5\% Deviation) Cloud 
4Fig. 4 Resourcesat-2 AWiFS NDVI images during February, May and July of 2019 and 2020
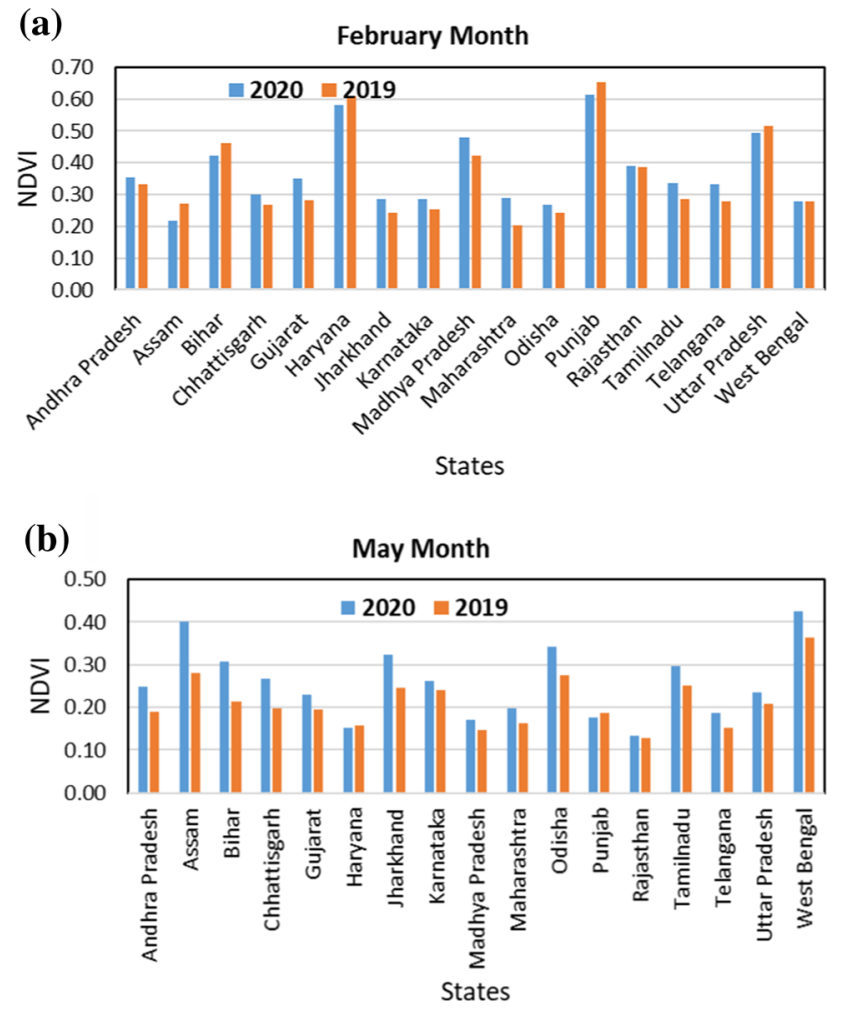

(c)
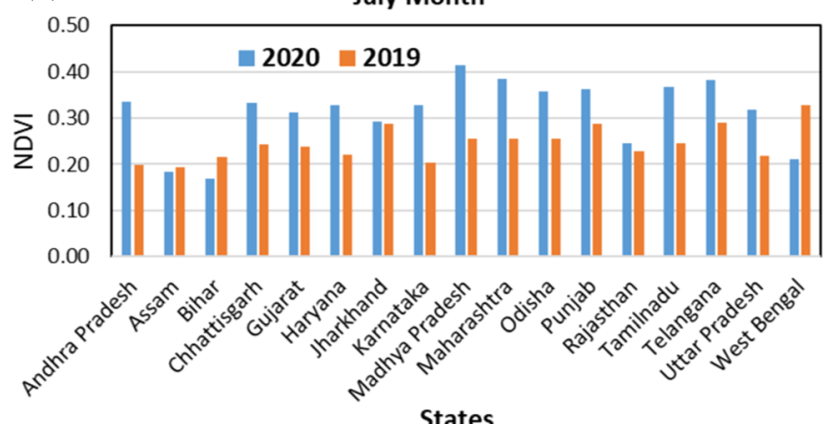

Fig. 5 Resourcesat-2 AWiFS NDVI comparison between 2019 and 2020 for Rabi, Zaid and Kharif seasons

the values are more or less close in February showing similar crop conditions in the pre-lockdown period, compared to 2019. However, in May, in many States, especially, Andhra Pradesh, Assam, Bihar, Jharkhand, Odisha, Tamil Nadu and West Bengal, the NDVI value of 2020 was significantly higher than 2019 . This indicates a higher crop area and better crop conditions during the lockdown period. These are the states known for Zaid cropping during March to May/June period and are showing increasing vegetation vigour during May (peak vegetative growth stage for
Zaid/summer crop). State-level average agricultural area NDVI value for 2020 was $4.8 \%$ higher than in 2019 in February, while it was $21.3 \%$ and $28.3 \%$ higher in May and July, respectively (Table 3 ). The $t$ test analysis showed that the difference between state-level NDVI values of 2019 and 2020 was highly significant for May and July but not significant for February.

During the post-lockdown period, i.e. in Kharif season, because of the good rainfall in June and July, most of the States had increased NDVI compared to that of 2019, except for the states of Bihar, Assam and West Bengal. Lower NDVI in Bihar and Assam might have been because of the impact of floods in these two states (Sphere India 2020) or due to the reduction in the jute and mesta area, which are mostly grown in Bihar, West Bengal and Assam. As per the estimates under the FASAL project (Ray and Neetu 2017), jute area in these states was 720.6 thousand hectare in 2019, while it was 676.6 thousand hectare in 2020.

To assess the cropped area, NDVI thresholding (with NDVI value $\geq 0.3$ ) was carried out on the images of 2019 and 2020 for February, May and July. The images are presented in Fig. 6, and the state-wise statistics of cropped area $\%$ (cropped area from image divided by total agricultural area from NRSC LULC map) are shown in Fig. 7. Though this may not exactly compute the crop area, it indicates the cropped area.

In February, i.e. before lockdown, the cropped area in northern states was similar for both years. However, area sown was higher in western states like Gujarat, Maharashtra, Telangana and Tamil Nadu. As mentioned earlier, this may be because of good post-monsoon rainfall in 2019,

Table 3 Comparison of state-level NDVI values and area sown percentage for 2019 and 2020, as derived from satellite data

\begin{tabular}{lllllllll}
\hline Parameters & \multicolumn{2}{l}{ February } & & \multicolumn{2}{l}{ May } & & & \multicolumn{2}{l}{ July } \\
\cline { 2 - 3 } NDVI values & 2019 & 2020 & & 2019 & 2020 & & 2019 & 2020 \\
Mean & 0.352 & 0.369 & & 0.211 & 0.256 & & 0.244 & 0.313 \\
Variance & 0.018 & 0.012 & & 0.007 & 0.004 & & 0.005 & 0.001 \\
$p$ value of $t$ test & $0.125(\mathrm{NS})$ & & $5.3 \times 10^{-5 * * *}$ & & $0.001 * *$ \\
Crop area $(\%)$ & & & & & & & \\
Mean & 35.51 & 41.17 & & 14.33 & 21.11 & & 21.27 & 35.98 \\
Variance & 596.2 & 499.5 & & 224.4 & 378.8 & & 93.2 & 203.8 \\
$p$ value of $t$ test & $0.007 * *$ & & $0.0005 * * *$ & & $0.0007 * * *$ \\
\hline
\end{tabular}

***Significant at the 0.001 level (2-tailed)

**Significant at the 0.01 level (2-tailed)

*Significant at the 0.05 level (2-tailed)

$N S$ non-significant 
Fig. 6 Map of the pixels with NDVI value $\geq 0.3$, indicating cropped area during 2019 and 2020 during Rabi (February), Zaid (May) and Kharif (July) seasons

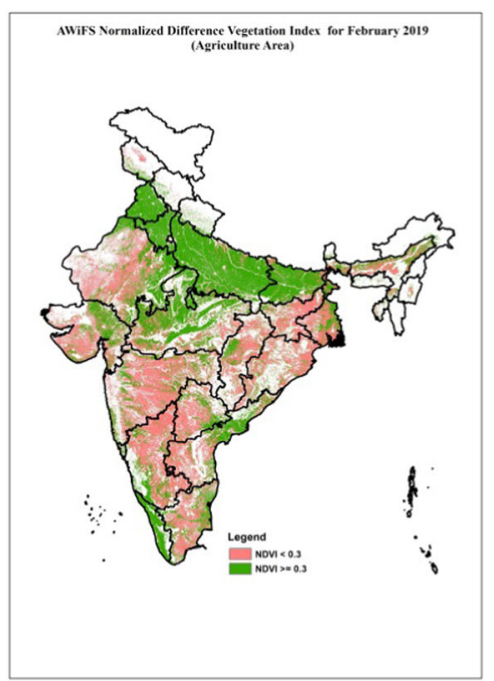

February 2019

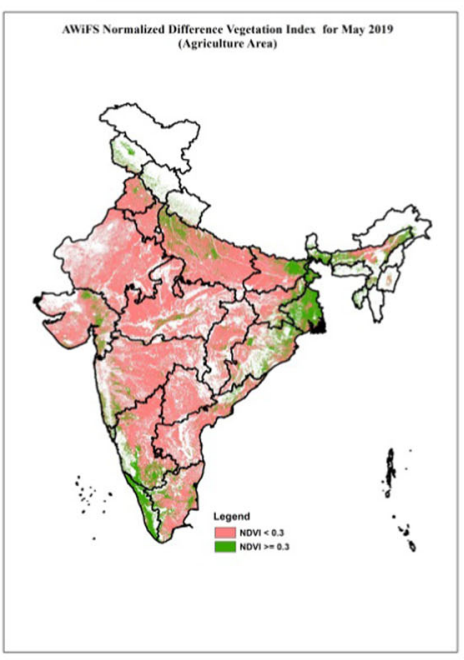

May 2019

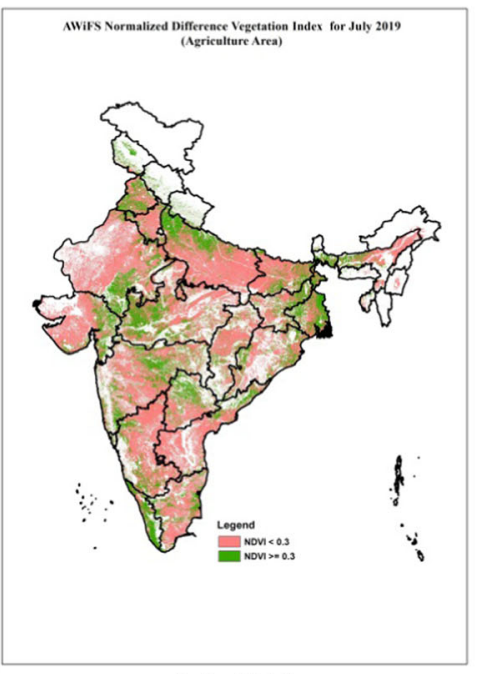

July 2019

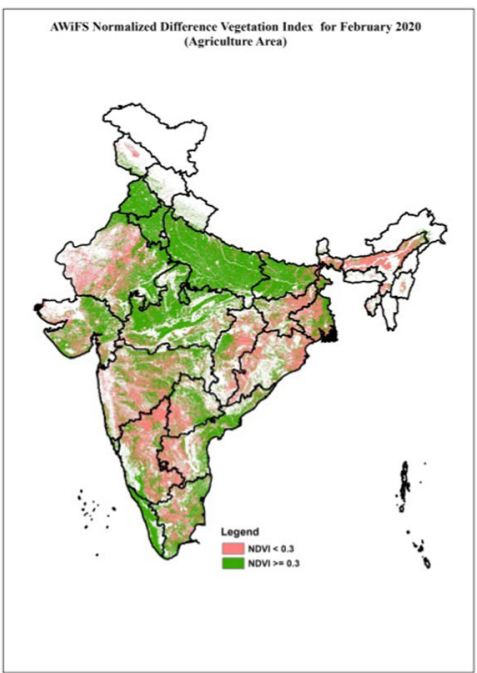

February 2020

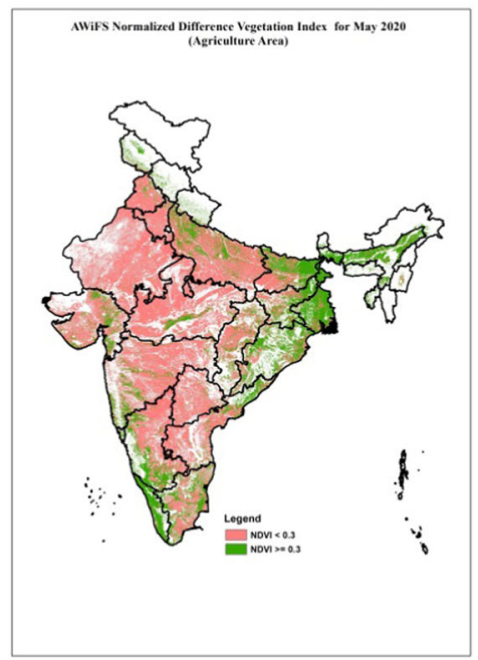

May 2020

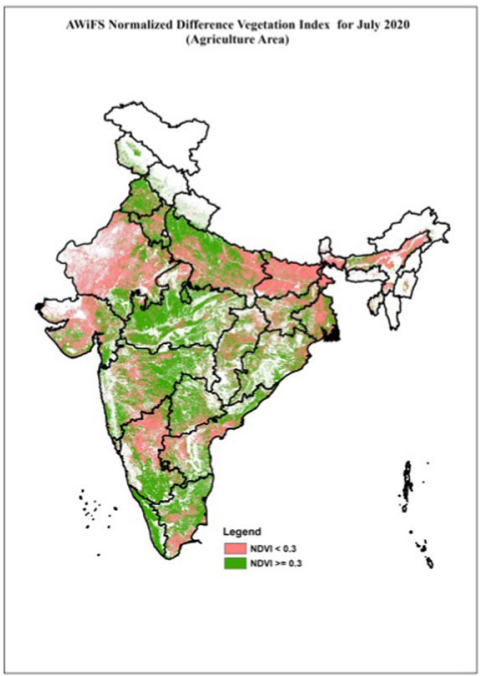

July 2020 
Fig. 7 State-level cropped area proportion (\%) of total agricultural area, derived using NDVI threshold of 0.3 during 2019 and 2020 for a Rabi,

b Zaid and c Kharif season
Rabi season

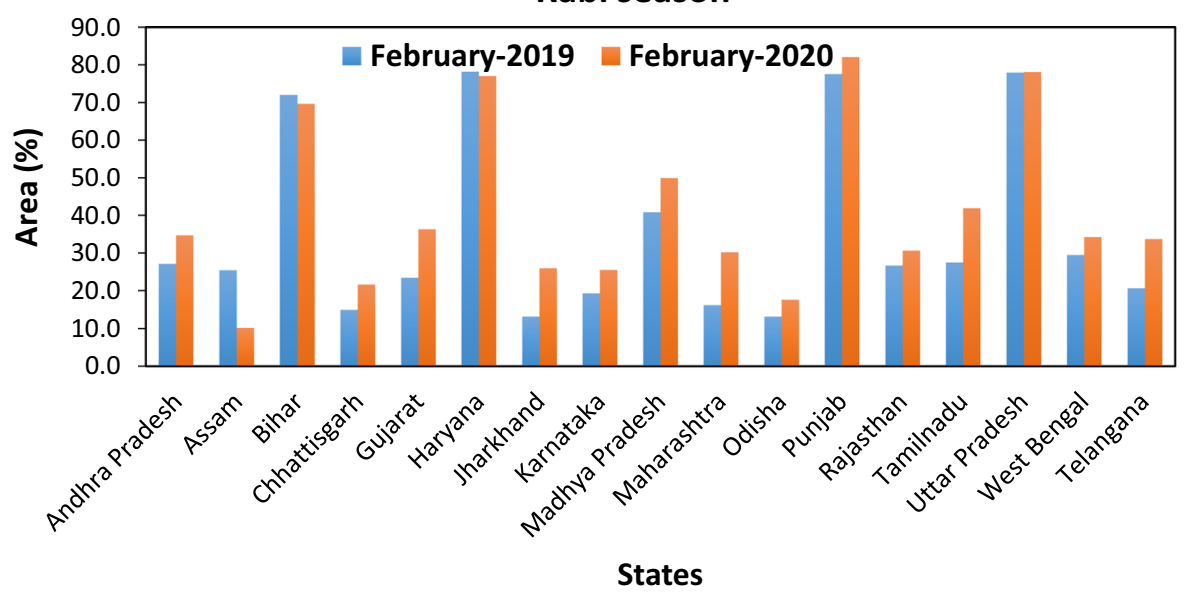

(a)

\section{Zaid season}

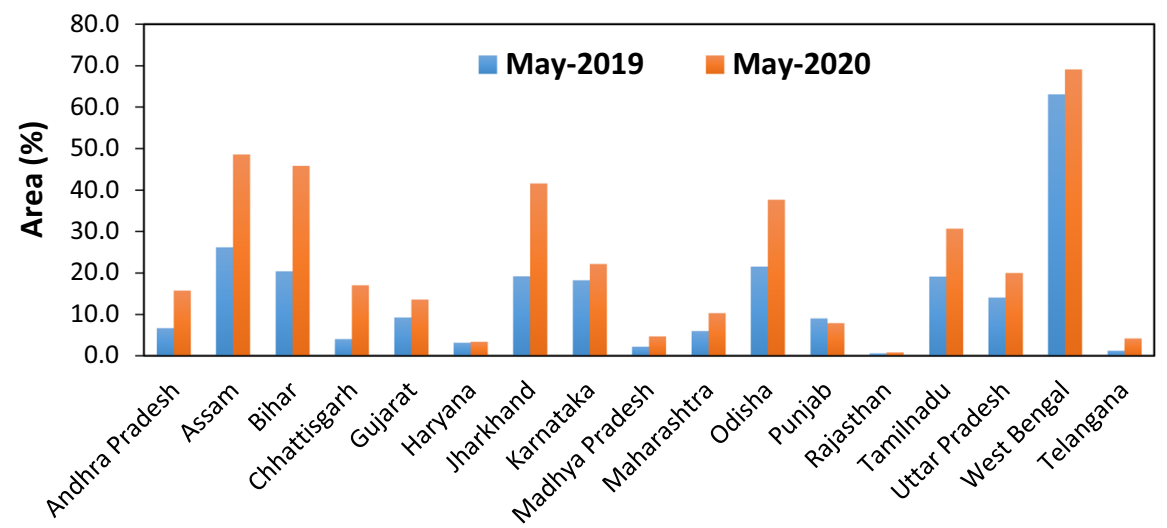

States

(b)

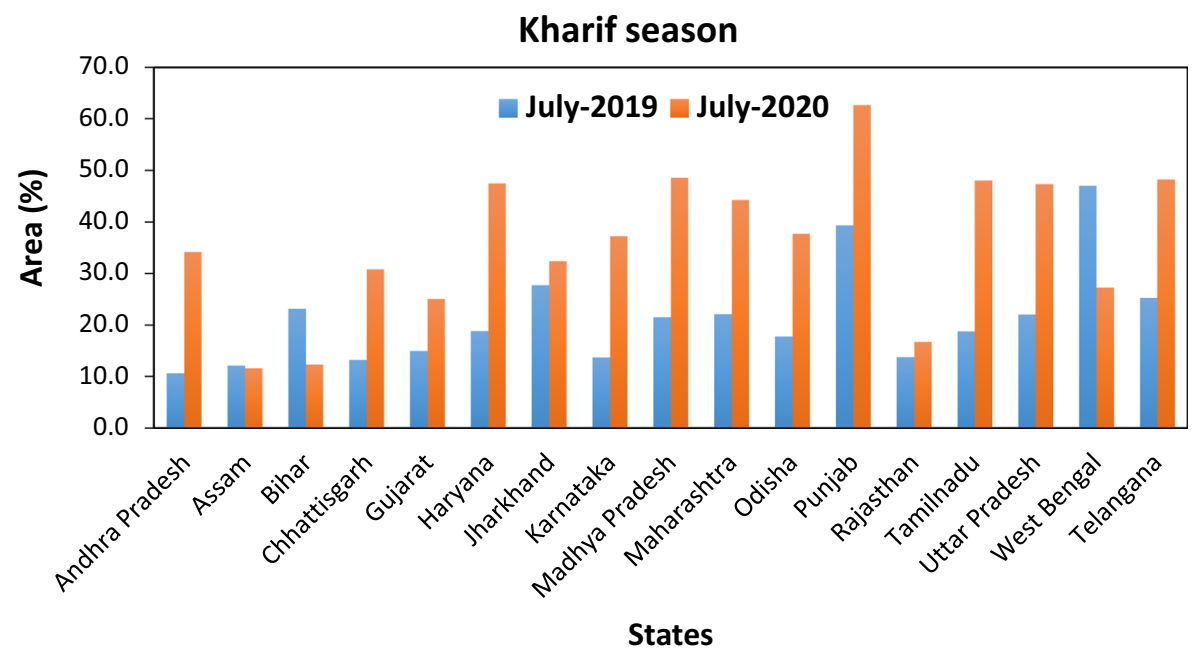

(c) 
which helped in the increase in Rabi sown area of rainfed crops because of high residual moisture (Figs. 6, 7).

In May, during the lockdown, most of the eastern states, i.e. Assam, Bihar, Chhattisgarh, Jharkhand and Odisha, had a significantly higher crop area in 2020 than in 2019 (Figs. 6, 7). Figure 2 shows that all these states had very good rainfall in the March-to-May period. The southern states like Andhra Pradesh, Telangana and Tamil Nadu also had a higher area in 2020. This has also been found from the government statistics (Sect. 3.2). State-level (for 17 states) average cropped area proportion (\%), derived from satellite data, for 2020 was $5.7 \%$ higher than 2019 in February, while it was $6.8 \%$ and $14.7 \%$ higher in May and July, respectively (Table 3). Though this shows a similar trend as the government statistics, discussed in Sect. 3.2, the values cannot be compared, as the government statistics is for total all-India cropped area, while the remote sensing-derived estimates are the average state-level area per cent of 17 major agricultural states. The $t$ test analysis showed that the differences between the state-level cropped area (\%) values of 2019 and 2020 were highly significant for February and very highly significant for May and July.

In July 2020 image, most of the states had higher areas compared to the corresponding period of 2019, except for Assam, Bihar, West Bengal and Rajasthan (Figs. 6, 7). As mentioned earlier, the higher area is due to very good rainfall in June and July (the sowing period), while the low area in three eastern states is due to the impacts of flood and cyclone.

\section{Discussion}

The lockdown to control the spread of COVID-19 pandemic was enforced in India on March 24th and continued up to May 31st. This lockdown time coincided with harvesting operations of Rabi/winter season crop and sowing time of Zaid/summer season crops. Globally, there are rising concerns over the impact of COVID-19 on agricultural production (Pu and Zhong 2020). However, in India, a large number of initiatives were taken to ease the situation (Nayyar 2020; Padhee and Pingali 2020). These included: (1) exemption of farm operations and supply chains from lockdown restrictions, (2) Indian Council of Agricultural Research (ICAR) issuing guidelines about harvesting and threshing of Rabi crops along with the advisories on handling post-harvest operations like storage and marketing of the farm produce more efficiently (ICAR 2020), (3) the government releasing the first instalment of the income support scheme (PM-Kisan Yojana) payment to farmers, (4) the central bank announcing a moratorium on agricultural loans, and many other initiatives. In addition to these government initiatives, there was a good amount of rainfall and its proper distribution during March-to-May period for the Zaid crop and June and July for the Kharif crop. Overall, the pre-monsoon period (March-May) had 20 per cent excess rainfall, and the monsoon period (JuneSeptember) had 9 per cent excess. Thus, the sowing of Zaid and harvesting of Rabi crops progressed well after the initial hiccup during lockdown (Mohan 2020). Due to intermittent rains during this period, the moisture content in the soil became suitable for the growth of crops (ET Bureau 2020).

All these factors caused a significant increase in crop area, as seen from the Agriculture Department's statistics and also satellite remote sensing data. The good rainfall not only increased the crop area but also improved the crop condition, as seen from the NDVI values and sown area maps and estimates. Also the CCE data (number of CCEs) derived from PMFBY portal showed that there was no impact on harvesting operations. Thus, the year 2020, even with COVID-19 lockdown, not only maintained the agricultural sowing and harvesting operations but also improved upon the previous year, which was also an agriculturally good year.

\section{Conclusion}

In this study, an attempt was made to use satellite remote sensing data from the Indian Resourcesat 2 AWiFS sensor to assess the impact of COVID-19 lockdown, from 24 March to 31 May 2020 on agricultural sowing and harvesting operations. Satellite data of before (February), during (May), and after (July) the lockdown period was used. Data were compared with the previous year, i.e. 2019, which was also an agriculturally good year. Crop sown area and crop condition (from NDVI data) were compared. Along with the satellite data, rainfall and crop statistics, including the number of CCEs, were compared. The results showed that the crop area and crop condition were much better during and post-lockdown period compared to 2019. This increase in crop area and enhancement in crop conditions were mostly due to better rainfall situations and the policy of the government providing relaxation for agricultural activities during the lockdown period. The results also showed that the crop harvesting operations must have been conducted smoothly, as there was no significant change in the number of CCEs conducted under PMFBY (using Smartphone).

The lockdown might have got long-term socio-economic impact on the livelihood of the farmers and agricultural workers, as discussed by Kumar et al. (2020) and FAO (2020). However, as of now, the analysis shows that India had good cropping season both in Zaid (lockdown period) and in Kharif (post-lockdown period) seasons, after 
an agriculturally very good Rabi season (pre-lockdown period).

Acknowledgements The study was carried out under the FASAL (Forecasting Agricultural output using Space, Agrometeorology, and Land-based observations) project of the Department of Agriculture, Cooperation, and Farmers' Welfare (DAC\&FW). Authors are grateful to the Secretary, DAC\&FW for all his support and encouragement. The authors are thankful to the Crops Division and Directorate of Economics and Statistics of DAC\&FW for providing crop area and production data. The Crop Cutting Experiment Information was provided by the Credits Division of DAC\&FW. Thanks are also due to the India Meteorological Department for rainfall data.

Author Contributions SS was involved in methodology, investigation, data analysis, preparation of figures, and graphs and writingoriginal draft. AR performed satellite data analysis. PT contributed to project management and writing-editing; SSR was involved in conceptualization, methodology, visualization, writing-review \& editing.

\section{Compliance with Ethical Standards}

Conflict of interest The authors declare that they have no known competing financial interests or personal relationships that could have appeared to influence the work reported in this paper.

\section{References}

Basnyat, P., McConkey, B., Meinert, B., Gatkze, C., \& Noble, G. (2004). Agriculture field characterization using aerial photograph and satellite imagery. IEEE Geoscience and Remote Sensing Letters, 1, 7-10. https://doi.org/10.1109/LGRS.2003. 822313.

Bastiaanssen, W. G. M., Molden, D. J., \& Makin, I. W. (2000). Remote sensing for irrigated agriculture: Examples from research and possible applications. Agricultural Water Management, 46, 137-155. https://doi.org/10.1016/S03783774(00)00080-9.

CWWG. (2020). Weekly reports of crop weather watch group. Department of Agriculture, Cooperation and Farmers' Welfare. Retrieved August 16, 2020, from http://agricoop.nic.in/weatherwatch.

DAC\&FW. (2016). Operational guidelines: Pradhan Mantri Fasal Bima Yojana (p. 60p). New Delhi: Department of Agriculture, Cooperation and Farmers Welfare.

Dadhwal, V. K., Singh, R. P., Dutta, S., \& Parihar, J. S. (2002). Remote sensing-based crop inventory: A review of Indian experience. Tropical Ecology, 43(1), 107-122.

Dev, S. M. (2020). Addressing COVID-19 impacts on agriculture, food security, and livelihoods in India, IFPRI book chapters, In: COVID-19 and global food security, chapter 7 (pp. 33-35). International Food Policy Research Institute (IFPRI). Available at https://www.ifpri.org/publication/covid-19-and-global-foodsecurity.

Elavarasan, R. M., \& Pugazhendhi, R. (2020). Restructured society and environment: A review on potential technological strategies to control the COVID-19 pandemic. Science of Total Environment, 725, 1-18. https://doi.org/10.1016/j.scitotenv.2020. 138858.

ET Bureau (2020). Summer crop sowing in full swing, procurement picks up. Retrieved August 16, 2020, from https:// economictimes.indiatimes.com/news/economy/agriculture/sum mer-crop-sowing-in-full-swing-procurement-picks-up/article show/75556928.cms.

FAO. (2020). Impact of the Covid-19 pandemic on food security and food systems. CL 164/10, 6-10 July 2020. Retrieved July 15, 2020, from http://www.fao.org/3/nd059en/ND059EN.pdf.

Garg, V., Aggarwal, S. P., \& Chauhan, P. (2020). Changes in turbidity along Ganga River using Sentinel-2 satellite data during lockdown associated with COVID-19. Geomatics Natural Hazards \& Risk, 11, 1175-1195. https://doi.org/10.1080/ 19475705.2020.1782482.

Ghosh, N., Rajeshwor, M., \& Preeti, A. (2019). Rainfall implications for food production in India: When and where. International Archives of the Photogrammetry, Remote Sensing \& Spatial Information Sciences. https://doi.org/10.5194/isprs-archivesXLII-3-W6-13-2019.

Holben, B. N. (1986). Characterization of maximum value composites from temporal AVHRR data. International Journal of Remote Sensing, 7, 1417-1434. https://doi.org/10.1080/ 01431168608948945.

ICAR. (2020). State-wise guidelines and advisory for farmers and farming sector during lockdown period due to COVID-19. Indian Council of Agricultural Research. Retrieved August 16, 2020, from https://icar.org.in/sites/default/files/State\%20level\%20advi sories $\% 20$ FINAL $\% 20$ submitted $\% 20$ word $\% 20$ file $\% 20$ for $\%$ 20publication\%202nd\%20April2020.pdf.

Kumar, A., Padhee, A. K., \& Kumar, S. (2020). How Indian agriculture should change after COVID-19. Food Security, 12, 837-840. https://doi.org/10.1007/s12571-020-01063-6.

Misra, I., Manthira Moorthi, S., Sharma, V., Sangar, G., \& Dhar, D. (2012). Full India NDVI map generation using Resourcesat-2 AWiFS data. Ahmedabad: Space Applications Centre, ISRO.

Mohan, V. (2020). Covid-19: Harvesting of wheat on track amid lockdown. Retrieved August 16, 2020, from http://timesofindia. indiatimes.com/articleshow/75370268.cms?utm_source=conten tofinterest\&utm_medium=text\&utm_campaign=cppst.

Mondal, S., Jeganathan, C., Sinha, N. K., Rajan, H., Roy, T., \& Kumar, P. (2014). Extracting seasonal cropping patterns using multi-temporal vegetation indices from IRS LISS-III data in Muzaffarpur District of Bihar, India. Egyptian Journal of Remote Sensing \& Space Science, 17, 123-134. https://doi.org/10.1016/j. ejrs.2014.09.002.

Nayyar, M. (2020). COVID-19 and agriculture: Strategies to mitigate farmers' distress. Retrieved August 16, 2020, from https://www. investindia.gov.in/team-india-blogs/covid-19-and-agriculturestrategies-mitigate-farmers-distress.

NRSA. (2007). Natural resources census: National land use and land cover mapping using multi-temporal AWiFS data (LULCAWiFS). Project Report 2005-2006. Document number: NRSA/RSGIS-AA/NRC/NLULC-AWiFS/PROJREP/R01/ JUN07 (p. 49). Hyderabad, India: National Remote Sensing Centre. Available at: https://bhuvan-app1.nrsc.gov.in/2dre sources/thematic/LULC250/0506.pdf.

NSSO. (2007). Manual on area and crop production statistics. CSOM-AG-01 (p. 111). New Delhi, India: National Sample Survey Organisation.

Padhee, A. K., \& Pingali, P. (2020). Lessons from a pandemic to repurpose India's agricultural policy. Nature India. Retrieved 12 May, 2020, from https://www.natureasia.com/en/nindia/article/ 10.1038/nindia.2020.83.

Panigrahy, S., \& Ray, S. S. (2006). Remote sensing. In K. L. Chadha \& M. S. Swaminathan (Eds.), Environment and agriculture (pp. 361-375). New Delhi: Malhotra Publishing House.

Patel, P. P., Mondal, S., \& Ghosh, K. K. (2020). Some respite for India's dirtiest river? Examining the Yamuna's water quality at Delhi during the COVID-19 lockdown period. Science of Total 
Environment, 744, 1-16. https://doi.org/10.1016/j.scitotenv. 2020.140851.

Patel, J. H., \& Oza, M. P. (2014). Deriving crop calendar using NDVI time-series. The International Archives of the Photogrammetry, Remote Sensing and Spatial Information Sciences. https://doi. org/10.5194/isprsarchives-xl-8-869-2014.

$\mathrm{Pu}$, M., \& Zhong, Y. (2020). Rising concerns over agricultural production as COVID-19 spreads: Lessons from China. Global Food Security, 26, 100409. https://doi.org/10.1016/j.gfs.2020. 100409.

Ray, S. S., \& Dubey, S. (2018). Space technology use in crop insurance: Experiences from India. In G. Sylvester (Ed.), Eagriculture in action: Drones for action (pp. 73-78). Bangkok: Food and Agriculture Organization of the United Nations and International Telecommunication Union.

Ray, S. S., \& Neetu (2017). Crop area estimation with remote sensing. In J. Delincé (Ed.), Handbook on remote sensing for agricultural statistics (chapter 5) (pp. 131-183). Rome: Global Strategy Improving Agricultural and Rural Statistics (GSARS), FAO Statistics Division (ESS), FAO.

Ray, S. S., Singh, S. K., \& Neetu (2016). Establishing an operational system for assessment and forecasting the impact of extreme weather events on crop production. Mausam, 67(1), 289-296.

Rouse, J. W., Haas, R. H., Schell, J. A., \& Deering, D. W. (1974). Monitoring vegetation systems in the Great Plains with ERTS. In Proceedings of third ERTS symposium, Greenbelt, MD, December 1974; NASA SP-351-1 (pp. 309-317).

Saxena, S., Choudhary, K., Saxena, R., Rabha, A., Tahlani, P., \& Ray, S. S. (2019). Comparison of agricultural situation of india for two years (2017 and 2018) using various drought assessment indicators during south west monsoon season in India. The International Archives of the Photogrammetry, Remote Sensing and Spatial Information Sciences. https://doi.org/10.5194/isprsarchives-XLII-3-W6-499-2019.

Singh, N. J., Kudrat, M., Jain, K., \& Pandey, K. (2011). Cropping pattern of Uttar Pradesh using IRS-P6 (AWiFS) data. International Journal of Remote Sensing, 32(16), 4511-4526. https:// doi.org/10.1080/01431161.2010.489061.
Singh, R. P., \& Chauhan, A. (2020). Impact of lockdown on air quality in India during COVID-19 pandemic. Air Quality, Atmosphere and Health. https://doi.org/10.1007/s11869-02000863-1.

Son, N. T., Chen, C. F., \& Cru, C. R. (2012). Mapping major cropping patterns in Southeast Asia from Modis data using wavelet transform and artificial neural networks. The International Archives of the Photogrammetry, Remote Sensing and Spatial Information Sciences, 39, 421-425. https://doi.org/10.5194/ isprsarchives-XXXIX-B3-421-2012.

Sphere India. (2020). Situation report 5: Flood situation in India. Retrieved July 25, 2020 from https://reliefweb.int/sites/relief web.int/files/resources/SITUATION\%20REPORT\%205\% 20FLOOD\%20SITUATION\%20IN\%20INDIA.pdf.

Wardlow, B. D., \& Egbert, S. L. (2002). Discriminating cropping patterns in the US Central Great Plains region using time-series MODIS 250-meter NDVI data-Preliminary results. In Proceedings, Pecora 15 and land satellite information IV conference (pp. 10-15). (13) (PDF).

WHO. (2020). Coronavirus disease (COVID-19) weekly epidemiological update. Geneva: World Health Organization. Retrieved October 04, 2020, from https://www.who.int/docs/defaultsource/coronaviruse/situation-reports/20201005-weekly-epiupdate-8.pdf.

Xiao, X., Boles, S., Frolking, S., Li, C., Babu, J. Y., Salas, W., et al. (2006). Mapping paddy rice agriculture in South and Southeast Asia using multi-temporal MODIS images. Remote Sensing of Environment, 100(1), 95-113. https://doi.org/10.1016/j.rse.2005. 10.004 .

Zhang, H., Lan, Y., Lacey, R., Hoffmann, W. C., \& Westbrook, J. K. (2011). Spatial analysis of NDVI readings with different sampling densities. Transactions of ASABE, 54(1), 349-354. https://doi.org/10.13031/2013.36244.

Publisher's Note Springer Nature remains neutral with regard to jurisdictional claims in published maps and institutional affiliations. 